\title{
Semen parameters in men with varicocele: DNA fragmentation, chromatin packaging, mitochondrial membrane potential, and apoptosis
}

Felipe Dieamant ${ }^{1,2}$, Claudia G. Petersen ${ }^{1,2}$, Ana L. Mauri1,2, Vanessa Conmar ${ }^{1}$, Mariana Mattila ${ }^{1}$, Laura D. Vagnini², Adriana Renzi ${ }^{2}$, Bruna P Costa², Camila Zamara1, João Batista A. Oliveira1,2, Ricardo L.R. Baruffi1,2, José G. Franco Jr. ${ }^{1,2}$

${ }^{1}$ Center for Human Reproduction Prof Franco Jr. - Ribeirão Preto, Brazil.

${ }^{2}$ Paulista Center for Diagnosis, Research and Training - Ribeirão Preto, Brazil.

\begin{abstract}
Objective: To evaluate varicocele effects on conventional semen parameters: sperm DNA fragmentation, chromatin packaging, mitochondrial membrane potential (MMP) and sperm apoptosis.

Methods: A cross-sectional study was carried out with semen samples from 2,399 men of couples who attended an infertility clinic. A total of $16.3 \%(391 / 2399)$ of the men were diagnosed with varicocele by a urologist.

Results: A regression analysis revealed that the percentages of sperm with DNA fragmentation, abnormal chromatin packaging, and abnormal MMP were significantly increased in individuals with varicocele, when compared to men without varicocele. Apoptosis was not influenced by varicocele. Conventional semen parameters were significantly worse in individuals with the disease. On the other hand, in men with varicocele, Spearman's correlation demonstrated that early apoptosis and abnormal MMP showed a positive and significant correlation with sperm DNA fragmentation.

Conclusion: Men with varicocele had worse semen parameters, including increased levels of sperm DNA fragmentation, inactive mitochondria, and abnormal chromatin packaging. These changes are possible causes of infertility in individuals with varicocele.
\end{abstract}

Keywords: varicocele, DNA damage, DNA fragmentation, chromatin packaging, inactive mitochondria, apoptosis

\section{INTRODUCTION}

Since 1955, there has been evidence that varicocele, defined as an abnormal dilatation of testicular veins in the pampiniform plexus and by retrograde blood flow in the internal spermatic veins because of incompetent or absent valves, has been associated with decreased sperm quality and thus, male infertility (Tulloch et al., 1955; Gat et al., 2004). This pathology is considered one of the main causes of male infertility; approximately $15 \%$ of the normal male population, and up to $40 \%$ of infertile men are believed to have clinical or subclinical varicocele (Witt \& Lipshultz, 1993; Pastuszak \& Wang, 2015).

Patients with varicocele present with abnormal spermatogenesis, but the exact pathophysiological mechanism by which varicocele promotes male-factor infertility still remains uncertain, although several possible causes have been proposed including testicular hypoxia due to venous stasis, hormonal dysfunction, reflux of renal and adrenal toxic metabolites, hypertension in the internal spermatic veins, and higher testicular temperature (Naughton et al., 2001; Saleh et al., 2003; Baccetti et al., 2006). Furthermore, high levels of oxidative stress, which arises from an unbalance between the over-production of reactive oxygen species (ROS) and the reduced total antioxidant capacity, which could result in alterations of semen parameters and sperm DNA integrity, have been observed in men with varicocele (Hendin et al., 1999; Smith et al., 2006).

High levels of sperm with DNA damage have been reported in the ejaculate of patients with varicocele compared to fertile men (Saleh et al., 2003; Chen et al., 2004). Plausible causes of sperm DNA fragmentation include increased levels of ROS, smoking, drug use, advanced age, chemotherapy or radiotherapy, and infections (Simşek et al., 1998; Hendin et al., 1999; Sergerie et al., 2007; Moskovtsev et al., 2006; Agarwal \& Saleh, 2002). In men with varicocele, sperm DNA damage is correlated with abnormal chromatin packaging, abnormal mitochondrial membrane potential (MMP), and apoptosis (Saleh et al., 2003; Zini \& Libman, 2006; Blumer et al., 2008; Sadek et al., 2011; Celik et al., 2013).

Recently, several studies have reported a relationship between sperm DNA damage and varicocele, but the mechanisms of sperm DNA damage vary among the different studies, and the sample size described may not be sufficient to generate a significant result; therefore, the aim of the present study was to evaluate the effects of varicocele on semen parameters and cytochemical parameters that include sperm DNA fragmentation, chromatin packaging, MMP, and sperm apoptosis.

\section{MATERIALS AND METHODS}

\section{Population}

We carried out a cross-sectional study with semen samples (one per subject), from 2,399 men from couples who attended an infertility clinic. There were two groups: the study group, which was made up of 391 patients with diagnosed varicocele, and the control group, which was made up of 2,008 patients without varicocele. The diagnosis of varicocele was made based on a physical examination. The same physician performed all the exams. All men from the couples who underwent infertility investigation between 2010 and 2015 were included, and the exclusion criteria were azoospermia, any known reproductive tract disease or hormonal therapy, chronic medical disorders, and antioxidant intake. Written informed consent for participation was obtained. The local ethics committee authorized this study.

\section{Sample collection}

Semen samples were collected in sterile containers by masturbation after a mean period of 3.6 days of sexual abstinence (range between 2 to 5 days). A portion of each semen sample was used to analyze the following parameters according to the WHO guidelines (WHO, 2010): volume $(\mathrm{ml}), \mathrm{pH}$, concentration $\left(x 10^{6} / \mathrm{ml}\right)$, percentage 
of spermatozoa with progressive motility (rapid + slow progression), percentage of total sperm motility, number of leukocytes, and percentage of live spermatozoa (vitality). Another portion of each semen sample was immediately processed for morphological analysis, which was performed at high magnification, using motile spermorganelle morphology examination (MSOME) criteria (Silva et al., 2012; Oliveira et al., 2014). The remainder of the semen samples was immediately processed for sperm DNA fragmentation analysis using the TdT (terminal deoxyribonucleotidyl transferase)-mediated dUTP nickend labelling (TUNEL) assay, sperm apoptosis analysis using the Annexin $\mathrm{V}$ assay, sperm chromatin packing/ underprotamination using chromomycin A3 $\left(\mathrm{CMA}_{3}\right)$ staining, and sperm mitochondrial membrane potential/ mitochondrial damage using MitoTracker Green.

\section{Determination of sperm DNA fragmentation}

DNA fragmentation in spermatozoa was measured using the TdT (terminal deoxyribonucleotidyl transferase)mediated dUTP nick-end labelling (TUNEL) assay as previously described (Franco et al., 2008, Oliveira et al., $2010 ; 2014)$. The number of cells with red fluorescence (TUNEL-positive) was expressed as a percentage of DNA fragmentation.

Determination of sperm chromatin packaging/ underprotamination

Sperm protamine deficiency (underprotamination)/ chromatin packaging was measured using chromomycin $A_{3}$ $\left(\mathrm{CMA}_{3}\right)$, as previously described (Franco et al., 2012). Two types of staining patterns were identified, namely, brightyellow fluorescence at the sperm head $\left(\mathrm{CMA}_{3}\right.$ positive/ abnormal chromatin packaging - underprotamination) and dull-yellow staining ( $\mathrm{CMA}_{3}$ negative/normal chromatin packaging - normal protamination). We established the percentages of spermatozoa with abnormal chromatin packaging.

\section{Determination of sperm mitochondrial membrane potential}

Sperm mitochondrial membrane potential (MMP) was determined using MitoTracker Green (MT-G) (Invitrogen - Molecular Probes ${ }^{\circledR}$, Eugene, OR, USA). Live sperm suspensions were incubated in a tube with $20 \mathrm{~nm}$ MitoTracker Green (MT-G) for 20 minutes at $37^{\circ} \mathrm{C}$ in the dark to avoid the breaking down of Molecular Probes ${ }^{\circledR}$. After this period, $0.5 \mathrm{ml}$ of Hoechst 33342 was added into the live sperm suspension and incubated for 10 minutes at $37^{\circ} \mathrm{C}$. This probe stains human sperm mitochondria according to MMP; the results are either MT-G positive or MT-G negative. MT-G positive refers to those that have active mitochondria that are colored green in the midpiece of the sperm. MT-G negative refers to the sperm that did not have labeled mitochondria in the mid-piece. The percentages of spermatozoa with altered MMP/ mitochondrial damage (i.e., absence of green fluorescence) were determined.

\section{Determination of early sperm apoptosis}

The Annexin- $V$ binding assay was used for apoptosis analysis. A volume of $20 \mu \mathrm{l}$ of prepared semen solution containing $1 \times 10^{6}$ cells $/ \mathrm{ml}$ was incubated with $100 \mu \mathrm{l}$ of Annexin-V-Fluos labeling solution (Annexin-Sol) for 15 minutes at room temperature in the dark. The Annexin-Sol consisted of $2 \mu \mathrm{l}$ of annexin-V-fluos reagent solution (Alexa fluor 488 annexin-v/dead cell apoptosis kit - Invitrogen), 1 $\mu \mathrm{l}$ of propidium iodide (PI), and $1 \mu \mathrm{l}$ of Hoechst 33342 diluted in $100 \mu$ of incubation buffer. After this period, the mixture (sperm cells and Annexin-Sol) was centrifuged at $600 \mathrm{~g}$ for 10 minutes and resuspended in $500 \mu$ of incubation buffer for examination. The percentages of apoptotic cells (defined as the number of spermatozoa that was stained green, and therefore positive for annexin- $\mathrm{V}$, but was not stained red with the propidium iodide dye divided by the total number of spermatozoa) were determined.

\section{Microscopy evaluation}

The quantitative evaluation of all tests (DNA fragmentation, chromatin packaging, apoptosis and MMP) was performed by analyzing at least 200 spermatozoa for each test that were assessed randomly on selected areas on the microscope slides using an Olympus BX50 fluorescence microscope. Texas Red and DAPI filters were used for the TUNEL method, while chromatin packaging, apoptosis and MMP were evaluated using the DAPI filters.

\section{Quality control}

To control for intra-observer and inter-observer variability, multiple fractions of semen samples were obtained from randomly selected patients. Each sample was observed at least three times by each observer (blinded to subject identity). A intra-observer and Interobserver variation of $\approx 0.5-1 \%$ and $0.5-7 \%$ respectively were obtained for each parameter analyzed: semen parameters according to the WHO guidelines, normality of the spermatozoon by MSOME, sperm TUNEL-positive, sperm $\mathrm{CMA}_{3}$-positive, sperm Annexin V-positive, and sperm MitoTracker Green-positive. These variations are comparable to those of classical sperm-quality parameters (Auger et al., 2000).

\section{Sample size}

The sample size was calculated by making a comparison between two proportions. A sample size of 300 subjects in each group had an $80 \%$ power to detect an increase of $10 \%$ with a significance level of 0.05 (two-tailed).

\section{Statistical analysis}

All variables were initially tested to determine variance homogeneity and data normality. The data is presented as the mean \pm standard deviation (SD) or as percentage. A logistic-regression analysis was performed to determine the variables that could be independently associated with sperm DNA damage. In addition, Spearman's correlation was used to verify and identify which cytochemical parameters (sperm packing, early apoptosis or abnormal MMP) are associated with sperm DNA fragmentation in the varicocele group.

The data management and univariate analysis were carried out using StatsDirect statistical software version 2.7.9 software (Cheshire, UK).

\section{RESULTS}

The analysis did not show a correlation between the presence of varicocele and the confounder parameters, including age, BMI, smoking habit, alcohol intake, and abstinence period (Table 1 ).

Statistically significant differences were found between the study and control group with respect to sperm volume, $\mathrm{pH}$, sperm concentration, morphology by MSOME, progressive and total motility, and vitality. There was no statistically significant difference in leukocyte concentration between the groups (Table 2).

Men with varicocele had a significantly increased percentage of DNA fragmentation, abnormal chromatin packaging ( $\mathrm{CMA}_{3}$ positive), and abnormal MMP in semen, then men without varicocele. There was no significant difference in early apoptosis between the groups (Table 2).

In the varicocele group, Spearman's analysis observed that early apoptosis and abnormal mitochondrial 
Table 1. Confounding parameters comparison, including age, BMI, smoking habit, alcohol intake, and abstinence period, between patients with varicocele and men without the pathology

\begin{tabular}{|l|c|c|c|c|c|}
\hline & \multicolumn{2}{|c|}{ Varicocele } & \multicolumn{2}{c|}{ Logistic regression } \\
\hline & Yes (n=391) & No (n=2008) & Odds Ratio & $\begin{array}{c}\text { 95\% Confidence } \\
\text { Interval }\end{array}$ & \begin{tabular}{c}
$\boldsymbol{p}$ \\
\hline Age (years)
\end{tabular} \\
\hline BMI $\left(\mathrm{kg} / \mathrm{m}^{2}\right)$ & $37.7 \pm 6.3$ & $37.8 \pm 6.6$ & 1.00 & $0.98-1.01$ & 0.97 \\
\hline Smoking habit (\%) & 10.5 & $28.1 \pm 19.8$ & 0.99 & $0.95-1.02$ & 0.35 \\
\hline Alcohol intake (\%) & 66.2 & 11.9 & 0.86 & $0.61-1.23$ & 0.41 \\
\hline Abstinence period (days) & $3.6 \pm 9.1$ & 67.0 & 0.97 & $0.77-1.22$ & 0.77 \\
\hline
\end{tabular}

\begin{tabular}{|c|c|c|c|c|c|}
\hline \multirow[b]{2}{*}{ Semen parameters } & \multicolumn{2}{|c|}{ Varicocele } & \multicolumn{3}{|c|}{ Logistic regression } \\
\hline & Yes $(n=391)$ & No $(n=2008)$ & Odds Ratio & $\begin{array}{c}95 \% \text { Confidence } \\
\text { Interval }\end{array}$ & $\boldsymbol{p}$ \\
\hline $\mathrm{pH}$ & $8.1 \pm 0.4$ & $8.0 \pm 0.4$ & 1.4 & $1.03-1.82$ & 0.02 \\
\hline Volume $(\mathrm{ml})$ & $2.5 \pm 1.1$ & $2.8 \pm 1.6$ & 0.90 & $0.82-0.99$ & 0.02 \\
\hline Concentration $\left(\times 10^{6} / \mathrm{ml}\right)$ & $44.4 \pm 45.5$ & $76.4 \pm 57.2$ & 0.98 & $0.97-0.99$ & $<0.001$ \\
\hline Progressive motility (\%) & $51.2 \pm 17.6$ & $57.0 \pm 16.5$ & 0.98 & $0.97-0.99$ & $<0.001$ \\
\hline Total motility (\%) & $59.1 \pm 17.2$ & $63.7 \pm 16.0$ & 0.98 & $0.97-0.99$ & $<0.001$ \\
\hline Normal forms (\%) & $0.4 \pm 0.9$ & $0.9 \pm 1.5$ & 0.70 & $0.61-0.81$ & $<0.001$ \\
\hline Vitality (\%) & $60.3 \pm 16.3$ & $65.3 \pm 15.7$ & 0.98 & $0.97-0.98$ & $<0.001$ \\
\hline Leukocytes $\left(\times 10^{6} / \mathrm{ml}\right)$ & $0.4 \pm 1.4$ & $0.7 \pm 0.8$ & 1.06 & $0.96-1.16$ & 0.22 \\
\hline DNA Fragmentation (\%) & $16.3 \pm 8.8$ & $15.3 \pm 8.5$ & 1.02 & $1.01-1.03$ & 0.03 \\
\hline $\mathrm{CMA}_{3}$ positive $(\%)$ & $58.9 \pm 14.8$ & $55.6 \pm 15.2$ & 1.02 & $1.01-1.03$ & 0.001 \\
\hline Abnormal MMP (\%) & $28.3 \pm 16.9$ & $25.4 \pm 16.2$ & 1.02 & $1.01-1.03$ & 0.03 \\
\hline Apoptosis (\%) & $18.8 \pm 7.4$ & $19.2 \pm 8.1$ & 0.99 & $0.97-1.01$ & 0.45 \\
\hline
\end{tabular}

membrane potential were the two cytochemical parameters that presented a positive and significant correlation with sperm DNA fragmentation. On the other hand, abnormal chromatin packaging and sperm leukocyte concentration (analyzed because of its association with ROS) showed no statistically significant differences in the present study. These results are shown in Table 3.

\section{DISCUSSION}

Our results demonstrated that patients with varicocele had lower total sperm counts, progressive and total sperm motility, vitality, and normal forms compared to the control group. In addition, these patients had increased percentages of spermatozoa with fragmented DNA. These findings corroborate literature data, which demonstrates that decreased semen quality - determined by the conventional sperm parameters - is associated with clinical varicocele (MacLeod, 1965; Vigil et al., 1994; Blumer et al., 2008 ). According to several studies, approximately $25 \%$ to $40 \%$ of men with semen alterations had varicocele, but the exact mechanism by which this condition impairs sperm quality remains unclear (Hauser et al., 2001; Sheehan et al., 2014; Pathak et al., 2016). It is known that ROS action has deteriorating effects on sperm function, including critical morphological and physiological modifications in both the testes and epididymis, especially in men with varicocele (Gil-Guzman et al., 2001).

Despite the availability of different procedures to diagnose varicocele, physical examination, and scrotal ultrasound remain the most commonly used methods. The term clinical varicocele refers to varicoceles detectable on palpation or visual inspection (Nasr Esfahani \& Tavalaee, 2012). In the present study, the varicocele diagnosis was made by the same urologist, with the patients in standing position and via scrotal inspection and palpation. The urologist evaluation determined only whether the patient had clinical varicocele, regardless of grade, since the number of men who had varicocele was low. In addition, Bozhedomov et al. (2014) didn't find any correlation between the grade of spermatic cord vein dilation and ROS production. The decision for additional exams was at the discretion of the urologist, and too few men were submitted to Doppler evaluation (less than $5 \%$ of the total population). Thus, we decided to consider in this study only the clinical examination as a criterion for the diagnosis of varicocele.

Data in the literature have demonstrated an increase in DNA fragmentation in men with varicocele and a clear association between oxidative stress and worse sperm parameters, including conventional parameters and sperm DNA damage (Bungum et al., 2007; Razi et al., 2011; Nasr Esfahani \& Tavalaee, 2012). This data and the outcomes of this study have demonstrated that there is an increase in DNA fragmentation in the sperm from the varicocele group compared to the control group.

Proper function and protection of sperm DNA depend on the remolded and condensed chromatin structure that is associated with an exchange of histone by protamine 
Table 3. Spearman's correlation within the varicocele group to verify the correlation between cytochemical parameters and sperm DNA fragmentation

\begin{tabular}{|l|c|c|c|}
\hline \multirow{2}{*}{$\begin{array}{l}\text { Varicocele group } \\
\mathbf{3 9 1}\end{array}$} & $\mathbf{r}$ & $\mathbf{9 5 \%}$ Confidence Interval & $\boldsymbol{p}$ \\
\cline { 2 - 4 } & 0.13 & 0.002 to 0.25 & 0.04 \\
\hline Early apoptosis (\%) & 0.10 & -0.03 to 0.23 & 0.11 \\
\hline $\mathrm{CMA}_{3}$ positive (\%) & 0.32 & 0.15 to 0.46 & $<0.001$ \\
\hline Abnormal MMP (\%) & -0.003 & -0.11 to 0.10 & 0.95 \\
\hline $\begin{array}{l}\text { Leukocytes concentration } \\
(\times 10 \% / \mathrm{ml})\end{array}$ & & \\
\hline
\end{tabular}

in the spermatid nucleus during the later stages of spermatogenesis -which is a crucial step in male fertility (Ward \& Coffey, 1991; Steger et al., 2000). This process is responsible for the compaction and stabilization of the sperm nucleus, and therefore, protects the sperm genome from oxidative stress, toxic metabolites, and excessive heat; a defect in this process makes the spermatozoa more susceptible to DNA damage, which is consequently associated with male infertility (Kosower et al., 1992; Aitken \& Krausz, 2001; Smith et al., 2006; Zini \& Libman, 2006). There is clinical evidence to show that abnormal sperm chromatin packaging is correlated with the reduced ability of spermatozoa to fertilize oocytes in normal conception or during ART procedures (Sakkas et al., 1996; Filatov et al., 1999; Talebi et al., 2008). In accordance with other authors that have used $\left(\mathrm{CMA}_{3}\right)$ to evaluate the DNA chromatin status in men with varicocele (Nasr-Esfahani et al., 2001; Singleton et al., 2007; Talebi et al., 2008), this study has demonstrated an increase in the levels of abnormal chromatin packaging in the semen from patients with varicocele. Other authors, using different methods, have also verified the chromatin packaging quality in men with varicocele, and similar results have been found (Salsabili et al., 2006; Sadek et al., 2011).

Mitochondria are important organelles that are present in several biologic processes, including spermatogenesis. Sperm motility depends on the normal function of the mitochondria that are in the mid-piece of the spermatozoa where ATP is produced, and it has been demonstrated that mitochondrial dysfunction is associated with reduced sperm functionality and male infertility (Amann, 1989; O'Connell et al., 2002; St John et al., 2005). Mitochondria are the major sources of intracellular ROS, and controlled ROS levels are needed for proper sperm function, including capacitation, the acrosome reaction, hyperactivation and fertilization (Kothari et al., 2010; Aitken et al., 2012). It is important to note that abnormal mitochondrial activity is related to increased levels of ROS, which may lead to decreased sperm motility and sperm DNA damage (Koppers et al., 2008; Sharma et al., 2013). Varicocele has been correlated with a high percentage of sperm with inactive mitochondria, and the oxidative stress found in patients with this condition may be a plausible explanation for this observation (Blumer et al., 2008; Koppers et al., 2008; Sharma et al., 2013). In our study, we observed that men with varicocele present with increased levels of abnormal mitochondrial membrane potential and therefore increased levels of inactive mitochondria, which is in accordance with literature data.

Germ cells die during normal spermatogenesis, by a process known as apoptosis, and is estimated to be responsible for the loss of up $75 \%$ of potential spermatozoa (Rodriguez et al., 1997; Sakkas et al., 2003; Said et al., 2004). Apoptosis is one of the main pathophysiological mechanisms of testicular dysfunction in men with varicocele, and there are three possible causes for apoptosis: higher testicular temperature, reduced levels of testicular testosterone, and the buildup of toxic metabolites in the semen (Sakkas et al., 2003; Benoff et al., 2004; Lee et al., 2009). In addition to early apoptosis, increased necrosis and sperm degeneration are also observed in patients with varicocele, probably because these processes are facilitated in these patients (Benoff et al., 2004, Nasr Esfahani \& Tavalaee, 2012). The increased molecular levels of ROS that result from varicocele would directly cause sperm DNA damage, and this has been demonstrated to be one of the most common ways to induce apoptosis (Simşek et al., 1998; Hendin et al., 1999; Cam et al., 2004). Consistent with the literature (Simşek et al., 1998; Hendin et al., 1999; Cam et al., 2004; Chen et al., 2004), this study has shown an increase in early apoptosis levels in patients with varicocele compared to the group of men without venous vascular impairment of the testes.

Possible sources of ROS are not entirely known, but spermatozoa and leukocytes have been demonstrated to be involved in the production of ROS at levels that are considered physiological (Cho et al., 2016). Abnormal spermatozoa and leukocytes, especially when activated by infection or inflammation, are potential sources of excessive ROS production and the consequent oxidative stress in the semen of patients with varicocele (Ochsendorf, 1999; Gil-Guzman et al., 2001). However, our study shows that leukocytes may not be involved in an extrinsic pathway of ROS production and do not appear to be a determinant in causing sperm DNA damage.

In conclusion, this study has shown a correlation between the presence of varicocele and a decrease in semen quality. In addition, the presence of this pathology increases DNA fragmentation, abnormal chromatin packaging, and abnormal mitochondrial activity levels. In men with varicocele, high levels of sperm mitochondrial inactivity and sperm apoptosis are associated with increased levels of sperm DNA fragmentation; however, DNA damage is not associated with sperm chromatin packaging and sperm leukocyte concentration. In patients with clinical varicocele, antioxidant intake and varicocele repairs should be considered as a feasible way to reduce sperm DNA damage. However, welldesigned studies are required to demonstrate, in details, how varicocele impairs fertility.

\section{CONFLICT OF INTERESTS}

The authors declare no conflict of interest.

\section{Corresponding author:}

Jose G Franco Jr.

Center for Human Reproduction Prof. Franco Jr.

Ribeirão Preto - SP - Brazil.

E-mail: crh@crh.com.br 


\section{REFERENCES}

Aitken RJ, Krausz C. Oxidative stress, DNA damage and the $Y$ chromosome. Reproduction. 2001;122:497-506. PMID: 11570956 DOI: 10.1530/rep.0.1220497

Aitken RJ, Jones KT, Robertson SA. Reactive oxygen species and sperm function--in sickness and in health. ] Androl. 2012;33:1096-106. PMID: 22879525 DOI: 10.2164/jandrol.112.016535

Amann RP. Can the fertility potential of a seminal sample be predicted accurately? J Androl. 1989;10:89-98. PMID: 2715106

Agarwal A, Saleh RA. Role of oxidants in male infertility: rationale, significance, and treatment. Urol Clin N Am. 2002;29:817-27. PMID: 12516754 DOI: $10.1016 / \mathrm{S} 0094-0143(02) 00081-2$

Auger J, Eustache $F$, Ducot B, Blandin T, Daudin M, Diaz I, Matribi SE, Gony B, Keskes L, Kolbezen M, Lamarte A, Lornage J, Nomal N, Pitaval G, Simon O, Virant-Klun I, Spira A, Jouannet P. Intra- and inter-individual variability in human sperm concentration, motility and vitality assessment during a workshop involving ten laboratories. Hum Reprod. 2000;15:2360-8. PMID: 11056133 DOI: $10.1093 /$ humrep/15.11.2360

Baccetti BM, Bruni E, Capitani S, Collodel G, Mancini S, Piomboni $\mathrm{P}$, Moretti E. Studies on varicocele III: ultrastructural sperm evaluation and $18, X$ and $Y$ aneuploidies. J Androl. 2006;27:94-101. PMID: 16400084 DOI: $10.2164 /$ jandrol.05081

Benoff SH, Millan C, Hurley IR, Napolitano B, Marmar JL. Bilateral increased apoptosis and bilateral accumulation of cadmium in infertile men with left varicocele. Hum Reprod. 2004;19:616-27. PMID: 14998961 DOI: 10.1093/humrep/deh139

Blumer CG, Fariello RM, Restelli AE, Spaine DM, Bertolla RP, Cedenho AP. Sperm nuclear DNA fragmentation and mitochondrial activity in men with varicocele. Fertil Steril. 2008;90:1716-22. PMID: 18155699 DOI: 10.1016/j.fertnstert.2007.09.007

Bozhedomov VA, Lipatova NA, Rokhlikov IM, Alexeev RA, Ushakova IV, Sukhikh GT. Male fertility and varicocoele: role of immune factors. Andrology. 2014;2:51-8. PMID: 2428566 DOI: 10.1111/j.2047-2927.2013.00160.x

Bungum $M$, Humaidan $P$, Axmon $A$, Spano $M$, Bungum L, Erenpreiss J, Giwercman A. Sperm DNA integrity assessment in prediction of assisted reproduction technology outcome. Hum Reprod. 2007;22:174-9. PMID: 16921163 DOI: 10.1093/humrep/del326

Cam K, Simsek F, Yuksel M, Turkeri L, Haklar G, Yalcin S, Akdas $A$. The role of reactive oxygen species and apoptosis in the pathogenesis of varicocele in a rat model and efficiency of vitamin E treatment. Int J Androl. 2004;27:228-33. PMID: 15271202 DOI: 10.1111/j.1365-2605.2004.00476.x

Celik O, Kutlu O, Tekcan M, Celik-Ozenci C, Koksal IT. Role of TNF-related apoptosis-inducing ligand (TRAIL) in the pathogenesis of varicocele-induced testicular dysfunction. Asian J Androl. 2013;15:269-74. PMID: 23274391 DOI: 10.1038/aja.2012.112
Chen $\mathrm{CH}$, Lee SS, Chen DC, Chien $\mathrm{HH}$, Chen IC, Chu YN, Liu JY, Chen WH, Wu GJ. Apoptosis and kinematics of ejaculated spermatozoa in patients with varicocele. J Androl. 2004;25:348-53. PMID: 15064311 DOI: 10.1002/j.1939-4640.2004.tb02799.x

Cho CL, Esteves SC, Agarwal A. Novel insights into the pathophysiology of varicocele and its association with reactive oxygen species and sperm DNA fragmentation. Asian J Androl. 2016;18:186-93. PMID: 26732105 DOI: 10.4103/1008-682X.170441

Filatov MV, Semenova EV, Vorob'eva OA, Leont'eva OA, Drobchenko EA. Relationship between abnormal sperm chromatin packing and IVF results. Mol Hum Reprod. 1999;5:825-30. PMID: 10460220 DOI: $10.1093 / \mathrm{molehr} / 5.9 .825$

Franco JG Jr, Baruffi RL, Mauri AL, Petersen CG, Oliveira JB, Vagnini L. Significance of large nuclear vacuoles in human spermatozoa: implications for ICSI. Reprod Biomed Online. 2008;17:42-5. PMID: 18616888 DOI: 10.1016/S1472-6483(10)60291-X

Franco JG Jr, Mauri AL, Petersen CG, Massaro FC, Silva LF, Felipe $V$, Cavagna M, Pontes A, Baruffi RL, Oliveira JB, Vagnini LD. Large nuclear vacuoles are indicative of abnormal chromatin packaging in human spermatozoa. Int J Androl. 2012;35:46-51 PMID: 21535011 DOI: $10.1111 /$ j.1365-2605.2011.01154.x

Gat Y, Bachar GN, Zukerman Z, Belenky A, Gornish M. Varicocele: a bilateral disease. Fertil Steril. 2004;81:424-9. PMID: 14967384 DOI: 10.1016/j.fertnstert.2003.08.010

Gil-Guzman E, Ollero M, Lopez MC, Sharma RK, Alvarez JG, Thomas AJ Jr, Agarwal A. Differential production of reactive oxygen species by subsets of human spermatozoa at different stages of maturation. Hum Reprod. 2001;16:192230. PMID: 11527899 DOI: 10.1093/humrep/16.9.1922

Hauser R, Paz G, Botchan A, Yogev L, Yavetz H. Varicocele: effect on sperm functions. Hum Reprod Update. $2001 ; 7: 482$ 5. PMID: 11556495 DOI: 10.1093/humupd/7.5.482

Hendin BN, Kolettis PN, Sharma RK, Thomas AJ Jr, Agarwal A. Varicocele is associated with elevated spermatozoal reactive oxygen species production and diminished seminal plasma antioxidant capacity. J Urol. 1999;161:1831-4. PMID: 10332447 DOI: 10.1016/S0022-5347(05)68818-0

Koppers AJ, De Iuliis GN, Finnie JM, McLaughlin EA, Aitken RJ. Significance of mitochondrial reactive oxygen species in the generation of oxidative stress in spermatozoa. J Clin Endocrinol Metab. 2008;93:3199-207. PMID: 18492763 DOI: $10.1210 /$ jc.2007-2616

Kosower NS, Katayose H, Yanagimachi R. Thiol-disulfide status and acridine orange fluorescence of mammalian sperm nuclei. J Androl. 1992;13:342-8. PMID: 1399837 DOI: $10.1002 / j .1939-4640.1992 . t b 00335 . x$

Kothari S, Thompson A, Agarwal A, du Plessis SS. Free radicals: their beneficial and detrimental effects on sperm function. Indian J Exp Biol. 2010;48:425-35. PMID: 20795359 
Lee JD, Lu LY, Cheng WH, Jeng SY. Dysregulated apoptosis through the intrinsic pathway in the internal spermatic vein of patients with varicocele. J Formos Med Assoc. 2009;108:612-8. PMID: 19666348 DOI: $10.1016 /$ S0929-6646(09)60381-8

MacLeod J. Seminal cytology in the presence of varicocele. Fertil Steril. 1965;16:735-57. PMID: 5842235 DOI: $10.1016 /$ S0015-0282(16)35765-X

Moskovtsev SI, Willis J, Mullen JB. Age-related decline in sperm deoxyribonucleic acid integrity in patients evaluated for male infertility. Fertil Steril. 2006;85:496-9. PMID: 16595239 DOI: $10.1016 /$ j.fertnstert.2005.05.075

Nasr-Esfahani MH, Razavi S, Mardani M. Relation between different human sperm nuclear maturity tests and in vitro fertilization. J Assist Reprod Genet. 2001;18:219-25. PMID: 11432114 DOI: 10.1023/A:1009412130417

Nasr Esfahani $\mathrm{MH}$, Tavalaee $\mathrm{M}$. Origin and role of DNA damage in varicocele. Int J Fertil Steril. 2012;6:141-6. PMID: 24520431

Naughton CK, Nangia AK, Agarwal A. Pathophysiology of varicoceles in male infertility. Hum Reprod Update 2001;7:473-81. PMID: 11556494 DOI: 10.1093/humupd/7.5.473

Ochsendorf FR. Infections in the male genital tract and reactive oxygen species. Hum Reprod Update. 1999;5:399420. PMID: 10582780 DOI: 10.1093/humupd/5.5.399

O'Connell M, McClure N, Lewis SE. The effects of cryopreservation on sperm morphology, motility and mitochondrial function. Hum Reprod. 2002;17:704-9. PMID: 11870124 DOI: 10.1093/humrep/17.3.704

Oliveira JB, Massaro FC, Baruffi RL, Mauri AL, Petersen CG, Silva LF, Vagnini LD, Franco JG Jr. Correlation between semen analysis by motile sperm organelle morphology examination and sperm DNA damage. Fertil Steril. 2010;94:1937-40. PMID: 20189558 DOI: 10.1016/j.fertnstert.2010.01.042

Oliveira JBA, Petersen CG, Mauri AL, Vagnini LD, Baruffi RLR, Franco Jr JG. The effects of age on sperm quality: an evaluation of 1,500 semen samples. JBRA Assist Reprod. 2014;18:34-41. DOI: 10.5935/1518-0557.20140002

Pastuszak AW, Wang R. Varicocele and testicular function. Asian J Androl. 2015;17:659-67. PMID: 25926610 DOI: 10.4103/1008-682X.153539

Pathak P, Chandrashekar A, Hakky TS, Pastuszak AW. Varicocele management in the era of in vitro fertilization/intracytoplasmic sperm injection. Asian J Androl. 2016;18:343-8. PMID: 27030086 DOI: $10.4103 / 1008-682 X .178482$

Razi M, Sadrkhanloo RA, Malekinejad H, Sarafzadeh-Rezaei F. Varicocele Time-dependently Affects DNA Integrity of Sperm Cells: Evidence for Lower In vitro Fertilization Rate in Varicocele-positive Rats. Int J Fertil Steril. 2011;5:17485. PMID: 25101162
Rodriguez I, Ody C, Araki K, Garcia I, Vassalli P. An early and massive wave of germinal cell apoptosis is required for the development of functional spermatogenesis. EMBO J. 1997;16:2262-70. PMID: 9171341 DOI: $10.1093 /$ emboj/16.9.2262

Sadek A, Almohamdy AS, Zaki A, Aref M, Ibrahim SM, Mostafa T. Sperm chromatin condensation in infertile men with varicocele before and after surgical repair. Fertil Steril. 2011;95:1705-8. PMID: 21292253 DOI: 10.1016/j.fertnstert.2011.01.008

Said TM, Paasch U, Glander HJ, Agarwal A. Role of caspases in male infertility. Hum Reprod Update. 2004;10:39-51. PMID: 15005463 DOI: 10.1093/humupd/dmh003

SakkasD, UrnerF, Bianchi PG, Bizzaro D, Wagner I, Jaquenoud N, Manicardi G, Campana A. Sperm chromatin anomalies can influence decondensation after intracytoplasmic sperm injection. Hum Reprod. 1996;11:837-43. PMID: 8671337 DOI: 10.1093 /oxfordjournals.humrep.a019263

Sakkas D, Seli E, Bizzaro D, Tarozzi N, Manicardi GC. Abnormal spermatozoa in the ejaculate: abortive apoptosis and faulty nuclear remodelling during spermatogenesis. Reprod Biomed Online. 2003;7:428-32. PMID: 14656403 DOI: $10.1016 / S 1472-6483(10) 61886-X$

Saleh RA, Agarwal A, Sharma RK, Said TM, Sikka SC, Thomas AJ Jr. Evaluation of nuclear DNA damage in spermatozoa from infertile men with varicocele. Fertil Steril. 2003;80:1431-6. PMID: 14667879 DOI: 10.1016/S0015-0282(03)02211-8

Salsabili N, Mehrsai A, Jalalizadeh B, Pourmand G, Jalaie $\mathrm{S}$. Correlation of sperm nuclear chromatin condensation staining method with semen parameters and sperm functional tests in patients with spinal cord injury, varicocele, and idiopathic infertility. Urol J. 2006;3:32-7. PMID: 17590850 DOI: $10.22037 /$ uj.v3i1.212

Sergerie M, Mieusset R, Croute F, Daudin M, Bujan L. High risk of temporary alteration of semen parameters after recent acute febrile illness. Fertil Steril. 2007;88:970-e1-7. PMID: 17434502 DOI: 10.1016/j.fertnstert.2006.12.045

Sharma R, Masaki J, Agarwal A. Sperm DNA fragmentation analysis using the TUNEL assay. Methods Mol Biol. 2013;927:121-36. PMID: 22992909 DOI: 10.1007/978-1-62703-038-0_12

Sheehan MM, Ramasamy $R$, Lamb DJ. Molecular mechanisms involved in varicocele-associated infertility. J Assist Reprod Genet. 2014;31:521-6. PMID: 24643631 DOI: $10.1007 / \mathrm{s} 10815-014-0200-9$

Silva LF, Oliveira JB, Petersen CG, Mauri AL, Massaro FC, Cavagna M, Baruffi RL, Franco JG Jr. The effects of male age on sperm analysis by motile sperm organelle morphology examination (MSOME). Reprod Biol Endocrinol. 2012;10:19. PMID: 22429861 DOI: 10.1186/1477-7827-10-19

Simşek F, Türkeri L, Cevik I, Bircan K, Akdaş A. Role of apoptosis in testicular tissue damage caused by varicocele. Arch Esp Urol. 1998;51:947-50. PMID: 9887572 
Singleton S, Zalensky A, Doncel GF, Morshedi M, Zalenskaya IA. Testis/sperm-specific histone $2 B$ in the sperm of donors and subfertile patients: variability and relation to chromatin packaging. Hum Reprod. 2007;22:743-50. PMID: 17110399 DOI: 10.1093/humrep/del439

Smith $\mathrm{R}$, Kaune $\mathrm{H}$, Parodi $\mathrm{D}$, Madariaga M, Rios $\mathrm{R}$, Morales I, Castro A. Increased sperm DNA damage in patients with varicocele: relationship with seminal oxidative stress. Hum Reprod. 2006;21:986-93. PMID: 16361286 DOI: 10.1093/humrep/dei429

Steger K, Pauls K, Klonisch T, Franke FE, Bergmann M. Expression of protamine-1 and -2 mRNA during human spermiogenesis. Mol Hum Reprod. 2000;6:219-25. PMID: 10694268 DOI: $10.1093 / \mathrm{molehr} / 6.3 .219$

St John JC, Jokhi RP, Barratt CL. The impact of mitochondrial genetics on male infertility. Int J Androl. 2005;28:65-73. PMID: 15811066 DOI : 10.1111/j.1365-2605.2005.00515.x

Talebi AR, Moein MR, Tabibnejad N, Ghasemzadeh J. Effect of varicocele on chromatin condensation and DNA integrity of ejaculated spermatozoa using cytochemical tests. Int J Androl. 2008;40:245-51. PMID: 15811066 DOI: $10.1111 /$ j.1365-2605.2005.00515.x
Tulloch WS. Varicocele in subfertility; results of treatment. $\mathrm{Br}$ Med J. 1955;2:356-8. PMID: 13240102 DOI: $10.1016 / \mathrm{S} 0022-5347(02) 80378-0$

Vigil P, Wöhler C, Bustos-Obregón E, Comhaire F, Morales P. Assessment of sperm function in fertile and infertile men. Andrology. 1994;26:55-60. PMID: 8042770 DOI: 10.1111/j.1439-0272.1994.tb00756.x

Ward WS, Coffey DS. DNA packaging and organization in mammalian spermatozoa: comparison with somatic cells. Biol Reprod. 1991;44:569-74. PMID: 2043729 DOI: 10.1095/biolreprod44.4.569

World Health Organization. WHO laboratory manual for the Examination and processing of human semen. 5th ed. Geneva: WHO; 2010.

Witt MA, Lipshultz LI. Varicocele: a progressive or static lesion? Urology. 1993;42:541-3. PMID: 8236597 DOI: 10.1016/0090-4295(93)90268-F

Zini A, Libman J. Sperm DNA damage: clinical significance in the era of assisted reproduction. CMAJ. 2006;175:495500. PMID: 16940270 DOI: $10.1503 / \mathrm{cmaj} .060218$ 